IRA International Journal of Management \& Social Sciences ISSN 2455-2267

Vol. 14, Issue 02 (Special Issue) pg. 80-86.

International Conference on Wellbeing: Lifespan Perspectives $0^{\circ}$ Practices for Sustainable

Communities, 2019.

\title{
Social Adjustment of Institutionalized Children under Need Care and Protection in Assam
}

Dr Rita Rani Talukdar ${ }^{1} \&$ Lipika Barman ${ }^{2}$

${ }^{1}$ HOD \& Associate Professor, Department of Psychology, Gauhati University, India.

${ }^{2}$ Research Scholar, Department of Psychology, Gauhati University, India.

DOI: $10.21013 /$ jmss.v14.n2sp.p10

(c) Authors.

Type of Review: Peer Reviewed under the Responsibility of the conference's Scientific Committee.

Disclaimer: The copyright to this work is retained by the authorship. This work contains the opinions $\sigma^{\circ}$ views of the authorship solely and the same are not the views or opinions of the IRA. IRA disclaims of any harm or loss caused due to the published content to any party. 


\begin{abstract}
Children are the backbone and future generation of the society and also preserve the societal culture and traditions of the society. Due to various reasons some children who are extremely poor, orphan, abandoned, sexually victimized children or neglected, children have to live without their families and they grow up in Child Care Institution (CCI). It is a temporarily organized residential care for children where alternative care is provided who are in need of care and protection. Institutionalization refers to the process of embedding something within an organization, social system or society as a whole. It aims to integrate fundamental values and objectives into the organization's culture and structure. Separation from the home or family environment, deprivation of parental care, love, affection, warmth, security, acceptance and discipline during childhood and adolescence may disrupt their normal development. The present study was conducted to study the social adjustment of these institutionalized children under the age group of 14 to 18 years. The sample was taken from child care institutions run by the Government of Assam and NGO of Assam. Total of 100 children was taken (50 male and 50 female). The adjustment Inventory for school student Developed by Sinha and Singh (1993) was used for the purpose. Descriptive statistics of social adjustment indicates low social stability among institutionalised children. Result revealed a significant difference between male and female in case of social adjustment. However, the result needs to be verified by using another test too.
\end{abstract}

\title{
INTRODUCTION:
}

Children are the most important human resource of the nation. They are the backbone and the future generation of society and also preserve the societal culture and traditions of the society. For the development of the society, all round development of the children is most essential. However, among them, some extremely poor, children with alcoholic of father, step-parents, sexually victimized children, and death of one or more parents, abnormal children, diceased parents and insecure environment, orphan, abandoned, neglected children have to live without their families and they grow up in Child Care Institution (CCI). It is a temporarily organized residential care for children where alternative care is provided who are in need of care and protection. According to Juvenile Justice (Care and Protection of Children) Act 2000, Child Care Institution is the last resort of the Best Interest of the Children. Children are living under need care and protection of an institution up to 18 years of age. There is provision for both boys and girls below 10 years kept in the same institution. There are separate institutions for the age group of 12 to 18 years. Separation from the home or family environment, deprivation of parental care, love, affection, warmth, security, acceptance and discipline during childhood and adolescence may disrupt their normal development. The present study aims to determine the different dimensions of adjustment such as emotional, social and educational adjustments of institutionalized children under the age group of 13 to 18 years.

\section{CHILD CARE INSTITUTION:}

A child care institution as defined under the JJ Act, 2015, means Children Home, Open Shelter, Observation Home, Special Home, Place of Safety, Specialised Adoption Agency and a Fit Facility recognized under the Act for providing care and protection to children, who are in need of such services.

Institutionalization refers to the process of embedding something within an organization, social system or society as a whole. Institutionalization is a process which translates an organizations code of conduct, mission, policies, vision and strategic plans into action guidelines applicable to the daily activities of its officers and other employees. It aims at integrating fundamental values and objectives into the organization's culture and structure.

Institutionalization is the placement of children in institutions, such as orphanages. Their placement in institutions during early critical developmental periods, for lengthy periods of time, is often associated with developmental delays due to environmental deprivation, poor staff to child ratios, and lack of early childhood stimulation.

\section{INSTITUTIONALIZED CHILDREN:}

Children who are in need of care and protection for various social and personal reasons, residing in a child care institution are called as institutionalized children.

\section{SOCIAL ADJUSTMENT:}

Social adjustment means the ability to adjust to one's social environment. It can be defined as a psychological process which frequently involves coping with new standards and values Social adjustment means adjusting in one's social environment. Social adjustment can be defined as a psychological process. It frequently involves coping with new standards and values. In the technical language of psychology, getting along with the members of the society as best as one can is called social adjustment. Social adjustment is an effort made by an individual to cope with standards, values and needs of a society in order to b accepted. It can be defined as a psychological process. It frequently involves coping with new standards and values. In the technical language of 
psychology, getting along with the members of the society as best as one can is called adjustment. It is a psychological process to cope up an individual with the social standard and values and needs of a society in order to be accepted.

\section{REVIEW OF LITERATURE:}

Youngleson (1973) studied the need to affiliate self-esteem in institutionalized children and compared 24 institutionalized children and a matched control group. The subjects were high school students between ages 15 -17 , who were in children's home. Findings show that the data gleaned from the social adjustment inventory confirmed that institutionalized children are less well adjusted and they manifest less self-esteem compared with a control group.

Anatharaman, (1992) conducted a study focused on the level of adjustment among institutionalized adolescents' shows that, neurotic items and adjustment problems with family matters are more seen with institutionalized children than their counterparts. It is worth noting that juvenile delinquents face more problems than institutionalized children. Though the overall adjustment scores are slightly higher in the non - institutionalized than the institutionalized group, the difference is not statistically significant. This shows that problems of adolescents are more contributed by the stage of development rather than other factors like intellectual or family care. Such a finding has important implications for planning and organizing mental health services for adolescents in general and institutionalized adolescents in particular.

Saraswatic. Hunshal, et. al. (2007) was conducted to study the social, emotional and educational adjustment of institutionalized children during 2003-05. The sample for the study comprised 148 children in the age group of 10-16 years residing in four juvenile institutions in Belgaum division, Karnataka state. Information about the adjustment of children was collected by using Sinha and Singh (1997) adjustment inventory. Results revealed that the majority of the institutional children had unsatisfactory social, emotional and educational adjustment and very few of them had good adjustment. Further, their age and academic performance had a significant influence on the adjustment of them. The adjustment of different types of abused children and their different periods of stay in the institution did not differ significantly.

A study on psychosocial aspects such as insecurity, self-esteem and adjustment problems among 252 adolescents institutionalized and 252 adolescents from socially and economically poor families but in parental care found that, those who are institutionalized significantly differed from who are in parental care. The study showed that institutionalized had higher insecurity lower self-esteem and emotional adjust mental problems (Jose, 2008).

Talukder. K. Hemasri (2015) conducted a study on "Cognitive Competence Among Institutionalised and NonInstitutionalised Children in Greater Guwahati Area". Total of 320 samples was taken for the study where 160 institutionalised and 120 non-institutionalised. From the findings of the study, it may be concluded that the noninstitutionalised children possess higher intellectual skills and perceptual competency compared to the institutionalised children. Hence, non-institutionalised children showed high cognitive competence than institutionalised children. The present study is one of the few studies conducted on the cognitive competence of the institutionalised children and the non-institutionalised children of the Greater Guwahati Area of the Kamrup Metropolitan District of Assam.

Sandhyarani M C and Rao C Usha (2016) conducted a study on "Perception of adjustment among institutionalised adolescent girls in selected districts of Karnataka." The universe comprises of 103 adolescent girls aged between 13 to 18 years residing in two Government institutions (Hubballi- 48 and Mysuru-55 adolescent girls), The study aimed to determine the different dimensions of adjustment such as home, peer, school, teacher and general adjustment among adolescent girls living in institutions. The study revealed that many of them have an adjustment problem while residing in the institution.

\section{RATIONALE OF THE STUDY:}

Institutionalization is the placing of children in institutions out of the home. An institution is any structure or mechanism of social order and cooperation governing the behaviour of a set of individuals within a given community. Institutions are identified with a social purpose and permanence, transcending individual human lives and intentions and with the making and enforcing of rules governing cooperative human behaviour Institutionalization has a deep impact on the life of a child.

Neglected by the parents, abandoned, orphan, ethnic conflict, extremely poor, domestic violence can be the reasons for the institutionalization of children. In the institution, children are living with numbers of children 
from the different social background and in the institution, they have to live with some proper rules and regulations and discipline and also have to adjust to the environment.

The present study will try to determine the level of social adjustments of institutionalized children under need care and protection. The findings will help them to understand their emotions in a proper way for better adjustment with the society and which in turn will help them later to be good citizens of the society. The findings of the study will also help them to access the aftercare facilities or programs organized by the government for effective development of the child.

\section{STATEMENT OF THE PROBLEM:}

To study the "Social Adjustment of Institutionalized children under need care and protection".

\section{RESEARCH QUESTION:}

- Are institutionalised children under need care and protection socially adjusted?

\section{OBJECTIVES OF THE STUDY:}

- To investigate the social adjustment of the institutionalised children under need care and protection in child care institutions in Assam.

- To differentiate the social adjustment of the institutionalised male and female children under need care and protection in child care institutions in Assam.

\section{THE HYPOTHESES OF THE STUDY:}

NH1. There will be no significant difference in social adjustment of the institutionalised male and female children under need care and protection in child care institutions in Assam.

\section{METHODOLOGY:}

VARIABLES UNDER THE STUDY:

Dependent Variable: Institutionalised Adolescents

Independent variable: Social Adjustment

POPULATION:

All the children residing in different child care institutions of Assam were the population for the study.

\section{SAMPLE:}

The sample for this study was taken from the Child Care Institutions (CCI) run by the government of Assam and NGO's in Assam. Total of 100 children will be taken for the study. The subjects will be classified as 50 male and 50 female institutionalized children. Their age range here between 14 to 18 years. They were selected randomly by using Purposive sampling technique from the following Child Care Institutions-

1. State Home for Girls, Jalukbari Guwahati

2. Assam Sishu Kalyan Sadan, Sundarbari, Guwahati

3. ROSS Children Home, Tangla, Udalguri

4. Kalyan Ashram for girls, Udalguri

5. Kalyan Ashram for boys, Udalguri

6. Children Home for boys, Fatasil Ambari, Guwahati

7. Children Home for boys, Lakhimpur

\section{CRITERIA FOR SELECTION OF SAMPLE:}

Only institutionalized school going children under need care and protection in child care institutions from the age range between 14 to 18 years of both the gender and who are residing in the institution at least for the duration of 2 months are selected for the study.

\section{PROCEDURE OF TEST ADMINISTRATION AND DATA COLLECTION:}

For collecting the data researcher has visited the various child care Institutions situated in various locations in Assam. The Superintendent of the respective Institution were approached and due permission was taken for collection of data. The researcher demonstrated the purpose of the study, regarding two psychological tests, their administering procedures etc to them.

After getting permission from the authority, the process of data collection began. A small class room was provided for meeting the children. They were informed about the research purpose and a detail description of 
the process of test administration. The test was a power test, so, there was no fixed time limit. The children were given instructions and were helped by making their doubts clear, whenever necessary. The responses were noted down.

\section{AGE GROUP AND RATIONAL:}

The age group of the sample selected for the study was 14 years to 18 years. Reasons for selecting this age group are:

- This particular age group of individuals are representing adolescents. As adolescence is the period of rapid growth and development of an individual both emotionally and socially as well as physically.

- Adolescents those who are residing in a child care institution they are the children in need care and protection and their psychological well being in highly important to take care.

\section{TOOLS:}

\section{SOCIO-DEMOGRAPHIC DATA SHEET:}

It is semi-structured, self-prepared Performa especially drafted for this study. It contains information about socio-demographic variables like age, sex, religion, education, socio-economic status, residence, parental status.

\section{ADJUSTMENT INVENTORY FOR SCHOOL STUDENT (AISS):}

Developed by Sinha and Singh (1993), the inventory was comprised of 60 items. The inventory seeks to segregate well-adjusted students from poor adjusted students in the three areas of adjustment Emotional, Social and Educational.

\section{STATISTICAL ANALYSIS:}

For this study, 100 samples have been collected of equal No. each of both the sexes. Among them 50 were male and 50 were female. A standardized psychological scale adjustment inventory for school students was used and scorings were done by the scoring methods mentioned in the manuals respectively. The data were analyzed by using SPSS latest version.

Table 1: Descriptive Statistics of social adjustment

\begin{tabular}{|l|l|l|l|l|}
\hline & Mean & Std. Deviation & $\%$ & N \\
\hline EMOTIONAL & 8.34 & 3.433 & 41.7 & 100 \\
SOCIAL & 9.07 & 2.479 & 45.35 & 100 \\
EDUCATIONA & 8.45 & 2.848 & 42.25 & 100 \\
L & 25.86 & 6.267 & 43.1 & 100 \\
AIS_TOTAL & & & \\
\hline
\end{tabular}

From the table 3, it is reflected that the mean value of Emotional adjustment is 8.34 which is 41.7 per cent and less than the average range which indicates low social stability, the mean value of Social adjustment is 9.07 which is 45.35 per cent which indicates aggressive behaviour. The mean value of Educational adjustment is 8.45 which is 42.25 per cent and indicates that the children of both the sexes are having interest in school activities.

Table 2: Gender wise distribution of Adjustment of Inventory

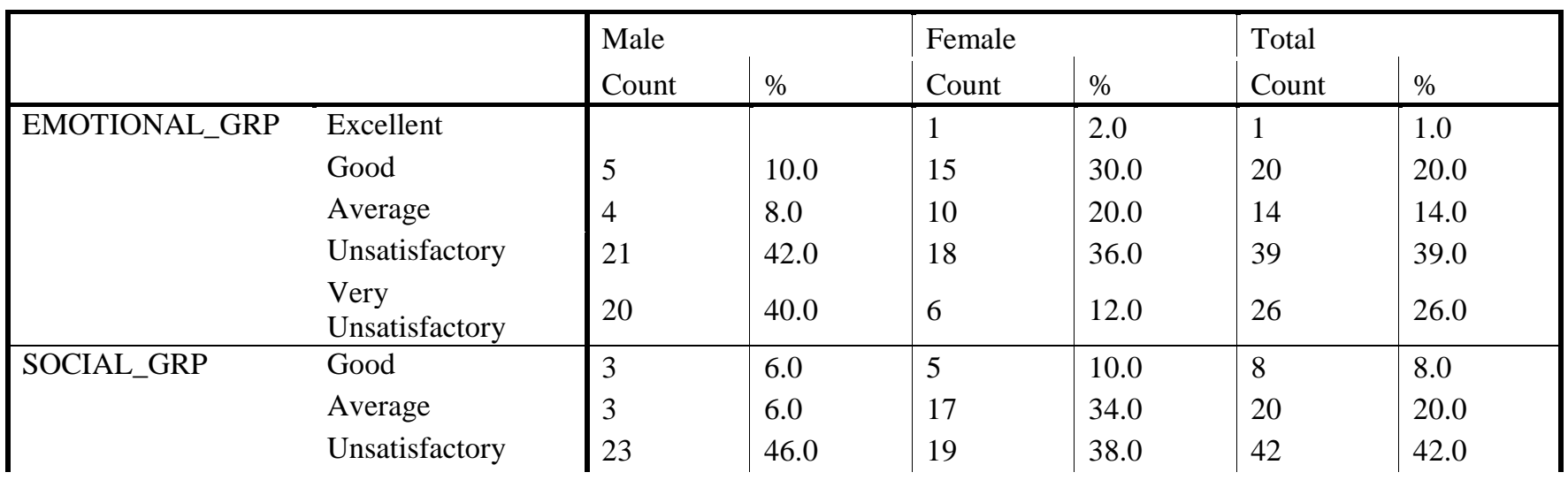




\begin{tabular}{|c|c|c|c|c|c|c|c|}
\hline & $\begin{array}{l}\text { Very } \\
\text { Unsatisfactory }\end{array}$ & 21 & 42.0 & 9 & 18.0 & 30 & 30.0 \\
\hline $\begin{array}{l}\text { EDUCATIONAL_G } \\
\text { RP }\end{array}$ & $\begin{array}{l}\text { Excellent } \\
\text { Good } \\
\text { Average } \\
\text { Unsatisfactory } \\
\text { Very } \\
\text { Unsatisfactory }\end{array}$ & $\begin{array}{l}1 \\
11 \\
23 \\
15\end{array}$ & $\begin{array}{l}2.0 \\
22.0 \\
46.0 \\
30.0\end{array}$ & $\begin{array}{l}1 \\
5 \\
20 \\
17 \\
7\end{array}$ & $\begin{array}{l}2.0 \\
10.0 \\
40.0 \\
34.0 \\
14.0\end{array}$ & $\begin{array}{l}1 \\
6 \\
31 \\
40 \\
22\end{array}$ & $\begin{array}{l}1.0 \\
6.0 \\
31.0 \\
40.0 \\
22.0\end{array}$ \\
\hline AIS_TOTAL_GRP & $\begin{array}{l}\text { Good } \\
\text { Average } \\
\text { Unsatisfactory } \\
\text { Very } \\
\text { Unsatisfactory }\end{array}$ & $\begin{array}{l}1 \\
4 \\
30 \\
15 \\
50\end{array}$ & $\begin{array}{l}2.0 \\
8.0 \\
60.0 \\
30.0 \\
100.0\end{array}$ & $\begin{array}{l}3 \\
22 \\
22 \\
3 \\
50\end{array}$ & $\begin{array}{l}6.0 \\
44.0 \\
44.0 \\
6.0 \\
100.0\end{array}$ & $\begin{array}{l}4 \\
26 \\
52 \\
18 \\
100\end{array}$ & $\begin{array}{l}4.0 \\
26.0 \\
52.0 \\
18.0 \\
100.0\end{array}$ \\
\hline
\end{tabular}

From the above table, it was found that in the emotional adjustment area $42 \%$ of male children have shown unsatisfactory adjustment whereas $36.0 \%$ of female children have shown unsatisfactory adjustment. Therefore it can be said that female children are comparatively more emotionally adjusted than male children.

In the social adjustment area, $46.0 \%$ of male children have shown unsatisfactory adjustment whereas $38.0 \%$ of female have shown unsatisfactory adjustment. Therefore it can be said that female children are slightly more socially adjusted than male children.

Likewise in the educational adjustment area, $46 \%$ of male children have shown unsatisfactory adjustment whereas $34.0 \%$ of female children have shown unsatisfactory adjustment, therefore we can say that female child is educationally adjusted than male children.

Table 3: T-Test: Significant difference between male and female

\begin{tabular}{|c|c|c|c|c|c|c|c|c|}
\hline & GENDER & $\mathrm{N}$ & Mean & Std. Deviation & $\mathrm{T}$ & Df & $\begin{array}{lr}\text { Sig. } & (2- \\
\text { tailed }) & P \\
\text { value }) & \end{array}$ & $\begin{array}{l}\text { Mean } \\
\text { Difference }\end{array}$ \\
\hline \multirow[t]{2}{*}{ EMOTIONAL } & Male & 50 & 9.60 & 3.037 & 3.929 & 98 & .000 & 2.520 \\
\hline & Female & 50 & 7.08 & 3.368 & & & & \\
\hline \multirow[t]{2}{*}{ SOCIAL } & Male & 50 & 9.78 & 2.332 & 2.975 & 98 & .004 & 1.420 \\
\hline & Female & 50 & 8.36 & 2.439 & & & & \\
\hline \multirow{2}{*}{$\begin{array}{l}\text { EDUCATIONA } \\
\mathrm{L}\end{array}$} & Male & 50 & 9.44 & 2.467 & 3.692 & 98 & .000 & 1.980 \\
\hline & Female & 50 & 7.46 & 2.880 & & & & \\
\hline \multirow[t]{2}{*}{ AIS_TOTAL } & Male & 50 & 28.82 & 5.259 & 5.339 & 98 & .000 & 5.920 \\
\hline & Female & 50 & 22.90 & 5.814 & & & & \\
\hline
\end{tabular}

Table 6 reveals a significant difference between male and female in case of social adjustment. In emotional stability area, the mean value of male children is 9.60 and female is 7.08 which is significant at 0.01 levels. It indicates female are more stable than male children. In social adjustment area, the mean value of male children is 9.78 and female is 2.332 which also significant at 0.01 levels and which indicates that female is more aggressive in behaviour than male children. In educational adjustment area, the mean value of male children is 9.44 and female is 2.88 which is again significant at 0.01 levels which indicates that female children are more interested in co-curricular activities than male children.

\section{CONCLUSION:}

- Female children are more socially adjusted then the male children as it is found a big difference at Mean Value.

\section{References}

[1]. Sandhyarani M C and Rao C Usha (2016). "Perception of adjustment among institutionalised adolescent girls in selected districts of Karnataka." International journal of advance multidisciplinary research, volume 3, issue 12-2016. 
[2]. Talukder K Hemasri and Talukder Rita Rani, Gauhati University. (2015). Psychological Differentiation of Institutionalised Children (Dr. Panch. Ramalingan and Dr. I. P. Borooah, Ed.) Guwahati: Puducherry Co-op.Book Society Ltd.,P.653.

[3]. Barooah Indranee Phookan, Mozumder Hoque Tahera,Gauhati University. (2015). Perceive Loneliness and Social Adjustment among Adolescent. (Dr. Panch. Ramalingan and Dr. I. P. Borooah, Ed.) Guwahati: Puducherry Co-op.Book Society Ltd., P.653.

[4]. The Juvenile Justice (Care and Protection of Children) Act, 2015

[5]. Hurlock, B.E. (1981).Developmental Psychology: A life span approaches (5th Ed.) Tata McGraw - Hill Publishing Company Limited, New Delhi.

[6]. Morgan Clifford T. King Richard A. Weisz John R. Schopler.J/ Introduction to psychology Tata McGraw Hill 1999.

[7]. S. Pastey Geeta and A. Aminbhavi Vijayalaxmi (2006), Impact of Emotional Maturity on Stress and Self Confidence of Adolescents. Journal of the Indian Academy of Applied Psychology, January 2006, Vol. 32, No.1, 66-70.

[8]. S.Reber, Rhianon Allen \& Emily. S. Reber(2009).Penguin Dictionary of Psychology, Penguin Books Ltd forth edition.

[9]. SARASWATI C. HUNSHAL AND V. GAONKAR (2007), A Study on Adjustment of Institutionalized Children. Karnataka J. Agric. Sci.,21(4) : (548-552) 2008

[10].Singha A.K.P \& Sing R.P. (1993) Adjustment Inventory for school students (AISS) National Psychological Corporation, Agra, India.

[11].Y. Singh and M Bhargava (1991). Manuals of Emotional Maturity Scale. Published by, National Psychological Corporation, Agra, India.

[12].Floyd Henry Allport. "Social Adjustments" Chapter 14 in Social Psychology. Boston: Houghton Mifflin Company (1924): 336-381. 